\title{
A18R aymaras, PERUANOS Y CHILENOS EN LOS ANDES ARIQUEÑOS: RESISTENCIA Y CONFLICTO FRENTE A LA CHILENIZACIÓN DEL NORTE DE CHILE
}

\section{Alberto Díaz Araya}

Profesor de la Universidad de Tarapacá, Iquique, Chile. Director del Taller de Investigaciones Culturales TINCU. Avenida Progreso $n^{0}$ 2298, Iquique, Región de Tarapacá, Chile. E-mail: nortealberto@hotmail.com.

\section{Resumen}

Este artículo reflexiona desde un punto de vista de la antropología histórica las reacciones y articulaciones que generaron las comunidades Aymaras del área de Arica entre los años 1901 y 1926, periodo reconocido como "chilenización", ante la presencia del Estado chileno, asumiendo posturas identitarias sociopolíticas en un ambiente de conflicto nacional.

\section{Palabras clave}

Aymaras, chilenización, identidades

\begin{abstract}
From an historical anthropology point of view, this article reflects on the reactions and relations that were generated by the Aymara communities of the area of Arica in the presence of the Chilean State, between the years 1901 and 1926 -period called "chilenización"- . These reactions assumed identity and sociopolitical positions in a national atmosphere of conflict.
\end{abstract}

Key words

Aymaras, Chilenización, Identities

\section{Introducción}

\begin{abstract}
El presidente recibió el siguiente telegrama del gobierno de Nueva Imperial, señor Martínez, por el cual le comunica el patriótico ofrecimiento hecho a la patria por 15 mil indios araucanos: Tengo el honor de comunicar a V.E: que hoy se han presentado a esta gobernación un grupo de ciento cincuenta indígenas entre caciques y caciquillos en representación de 15 mil indios aptos para el servicio militar, a saludar al infraescrito como representante del ejecutivo y a ofrecer su concurso a Chile en caso de peligro nacional. Venían con cornetas y banderas chilenas a la cabeza de la columna, mandados por el cacique principal don Ignacio Nelcumán. Manifestación grandiosa pueblo Imperial impresionado patrióticamente. Martínez. (Diario "El Ferrocarril", 25 de diciembre de 1918)
\end{abstract}

$\mathrm{H}^{-2}$ emos querido iniciar este artículo centrándonos en la manera en que era concebida la población indígena en el territorio chileno durante las primeras décadas del siglo XX, principalmente 
catalogada y caricaturizada bajo el rótulo de "indómito pueblo araucano". Esta imagen, construida durante la colonia hispana, fue acrecentándose como una característica del espíritu guerrero de los mapuche, y a la postre el pueblo chileno la heredó como parte de su identidad cultural. $^{1}$

Este texto transcrito del periódico "El Ferrocarril" editado en Arica en el año 1918 posee, según nuestro parecer, dos elementos que son interesantes. El primero, se refiere a que la autoridad gubernamental considera a los mapuche como "indígenas" y reconoce a sus jefaturas o caciques, quienes cuentan con cierta credibilidad y prestigio frente al Estado chileno. Lo segundo, se refiere al "espíritu patriótico" de los "indios araucanos", que acuden en masa para engrosar las filas de las unidades castrenses, ya sea para efectuar el servicio militar o para combatir "en caso de peligro nacional".

Ambos elementos demuestran cómo fueron concebidos los indígenas hacia inicios del siglo $X X$. Cabría entonces preguntarnos cómo este fragmento es publicado en el extremo norte de Chile ${ }^{2}$ ¿para resaltar el espíritu patriótico unificado o para demostrar que los indígenas son ante todo "chilenos"? ¿Qué sucede, entonces? Los indígenas que habitan las serranías andinas o la meseta altiplánica en la zona interior de Arica ¿son reconocidos?, ¿se los identifica como aymaras, como ciudadanos peruanos o como patriotas chilenos como era el caso con los Mapuche? Éstas son algunas de las interrogantes que actúan como hilo conductor de este artículo.

El tema de las identidades, regionales o nacionales, no está del todo dilucidado en este período. En un extremo están los sectores, -inclusive investigadores- cuyo objetivo es unificar bajo la sombra del Estado chileno todos los rincones del territorio, homogeneizar la sociedad y sus expresiones culturales. De este modo los símbolos patrios como el escudo, el himno nacional, los héroes, la bandera, la danza de la "cueca" y el "huaso" son los símbolos de una nación con un solo ideal, un solo cuerpo y un solo espíritu nacional. Esta identidad se construye y se maneja desde la metrópolis o desde los grupos de poder y se expande hacia la periferia o las regiones fronterizas como es el caso del norte chileno. ${ }^{3}$ Por otro lado, existe un sector que intenta exaltar el espíritu localista, en estricto rigor "chauvinista" y ambiciona destacar las diferencias con el resto del país.

Ambas posturas, que tienen defensores y detractores, permiten adentrarnos a un escenario social y cultural complejo y poco explorado por la historiografía del área rural de Arica. Esta región fue asiento de las comunidades aymara desde épocas precolombinas. Después de 1821 formaron parte de la naciente república peruana. Hacia finales del siglo XIX, se vieron envueltos en el conflicto entre Chile y Perú por los territorios de Tacna y Arica y las zonas aledañas que concluyó en 1929.

\footnotetext{
${ }^{1}$ Para una discusión crítica sobre contextos construidos o elaborados afanosamente por distintos investigadores, sugerimos ver Hobsbawn y Ranger (1989). Una discusión detallada sobre interpretaciones de conceptos identitarios se puede encontrar en Larraín (2001: 49-74). Y Un análisis del pasado mapuche en Bengoa (2000).

${ }^{2}$ Para la dinámica de los nacionalismos, las identidades y el accionar de la prensa ver Anderson (1983).

${ }^{3}$ Villalobos sostiene este tipo de alegatos afirmando, en un tono intolerante, que nuestro país "ha sido realmente una nación, con una población relativamente homogénea y con una cultura de gran uniformidad. En el gran cuadro del país, los indígenas, o mejor dicho, los mestizos de aspecto más autóctono, han sido agrupaciones de poca dimensión, en que sus costumbres
} 
La intención de este trabajo es ilustrar un momento de la historia nacional (y regional) que ha sido analizada solamente desde el plano político y diplomático y no ha tenido en cuenta la versión de sus actores. Para ellos usaremos como ejemplo el caso de los comuneros de la localidad de Putre. Pensamos que la historia debería dejar de lado los análisis fríos y estáticos de sucesos políticos, estructuras administrativas estatales o eventos bélicos, para escudriñar en la memoria colectiva de la población, en sus formas de vida y sus mentalidades. Para ello, es necesario dar prioridad a los testimonios e integrar las teorías y metodologías que la sociología y la antropología aportan ${ }^{4}$. En tal sentido, la historia social que integra documentos y testimonios, abre nuevas vías para acercarnos al pasado de la gente que habita las cumbres andinas y el inhóspito desierto norteño. ${ }^{5}$

Nuestra propuesta es que los campesinos de la zona interior de Arica actuaron como ciudadanos peruanos para rearticular (y también resistir) las políticas chilenizadoras aplicadas en la zona. Ellos no habrían asumido una postura de afirmación de su identidad aymara, debido a que, en la mayoría de los casos, la resistencia obedecía a conflictos con la autoridad cívica, con los procesos de reclutamientos y con intereses particulares). No obstante, siguiendo la postura de Lakatos sobre "el cinturón de hipótesis", podríamos argumentar, que en la zona de puna o altiplano y durante los primeros años de ocupación chilena, la identidad se centró más en la dinámica étnica que en la ciudadana y se mantuvieron las estructuras comunitarias y los ritos y costumbres propios de la cultura aymara. Sin embargo, gradualmente fueron asumiendo los colores de la identidad nacional chilena que se consolidó ya avanzado siglo XX.

\section{Llegan los "rotos". La política administrativa chilena en el departamento de Arica post guerra del Pacífico ${ }^{6}$}

Tras el triunfo en la guerra del Pacífico (1879 - 1883), el Estado chileno, necesitó implementar una organización que le permitiera administrar eficientemente la zona en litigio (Arica - Tacna), obtener un dominio soberano del territorio y la aprobación de la población local que debería votar en el Plebiscito acordado en el Tratado de Ancón de 1883. ${ }^{7}$ Para ello se construyó caminos hacia los valles y sistemas de drenaje de acequias en Tacna, se implementaron campañas de salubridad y de alfabetización, y se estableció controles sobre las naves que transitaban por la costa y sobre los hitos fronterizos, etc. Con esta finalidad, hacia el año 1885 un decreto administrativo estableció los límites

propias tenían algo de reminiscencia anecdótica bajo la cultura dominante. Así ocurría con los escasos descendientes de los aimaras y de los araucanos" (Villalobos 2002: 275). Posturas similares en Góngora (1981) y Vial (1983).

${ }^{4}$ Sobre esta temática ver Pavilack (2000), Le Goff (1988), Braudel (1952), Duby y Ariés (2001), y De Certau (1996) entre otros.

${ }^{5}$ Es necesario considerar aspectos metodológicos en la realización de este trabajo, el cual contó con una revisión sistemática de los documentos de la ex-Subdelegación de Putre (ASP), la ex-Intendencia de Tacna y la Gobernación de Arica, ambos en el archivo histórico Vicente Dagnino (AHVD); todos materiales archivísticos en bóvedas dependientes de la Universidad de Tarapacá, además del fichaje del Conservador de Bienes Raíces de Arica (CBRA). Además de contempló la realización de entrevistas a lugareños de las comunidades de Putre, Socoroma y Parinacota. Toda la información fue debidamente ordenada y clasificada, triangulando todos los antecedentes tanto documentales como los relatos orales: información que se expone en este estudio.

${ }^{6}$ Mayores antecedentes sobre el sistema administrativo chileno impuesto en Tacna y Arica en Diaz, Mondaca y Ruz (2000).

${ }^{7}$ Una descripción mucho más detallada sobre este periodo en Diaz op cit pp. 147. También en Herrera, Pamela et al "Algunos antecedentes relacionados con la problemática política y social de Tacna y Arica. 1900 - 1929", seminario de título de profesor de Historia y Geografía, Universidad de Tarapacá, 1995. 
de la Intendencia de Tacna, de las gobernaciones y de las subdelegaciones. Dichas subdelegaciones estaban organizadas de acuerdo a una estructura definida que estaba bajo el control del gobierno central a través de la jurisdicción del Ministerio de Relaciones Exteriores. (En la zona en litigio el Ministerio del Interior no podía emitir ni designar cargos administrativos.)

En términos de relaciones políticas, el Gobierno central designaba todos los cargos de la administración pública de la zona con el propósito de controlar todas las actividades de la intendencia de Tacna. A éste deberían dirigirse todo tipo de consultas, partes, informaciones secretas, censos, etc. Después venían, en orden jerárquico, el Intendente que, usualmente, era un antiguo militar, dadas las condiciones bélicas de la zona. Los cargos de gobernadores eran designados desde Santiago y recaían tanto en civiles como militares, aunque se privilegiaba la condición militar. Posteriormente, venía la Junta de Alcaldes, nombrados por el Presidente. Los cargos de subdelegados recaían en ciudadanos chilenos vecinos de Arica o migrantes del centro del país que gozaban de la confianza de la junta de alcaldes, el intendente y el gobernador. En la mayoría de los casos ellos debían, avecindarse en sectores rurales, zonas inhóspitas de complicado acceso, donde residían los campesinos. El subdelegado Rural, era el encargado de llevar a la práctica las políticas administrativas en las zonas interiores. A él le debían respeto los inspectores de distrito, los jueces de letras, los policías y la comunidad campesina en general.

Donde se presentaba una particularidad es en el nombramiento de inspectores de distrito y jueces de letras de las diferentes subdelegaciones. Estos eran miembros activos de las comunidades aymara. Se trataba de comuneros que gozaban de la confianza del subdelegado, de la comunidad y, también, del gobierno local. Esta información resulta importante debido a que, en una zona de conflicto de Soberanía, se contaba con la participación de comuneros peruanos para ejercer cargos públicos. Esta situación se torna comprensible si tenemos en cuenta el plebiscito, ya que serían de los habitantes de la región de Tacna y Arica, incluso los de las zonas interiores, los que tendrían que emitir el sufragio para elegir con qué Estado se quedaban (Chile o Perú). En tal sentido, las autoridades buscaban ganarse la confianza en la población, sobre todo la campesina, que se consideraba como la más reticente a la política administrativa chilena. Por otro lado, contar con el apoyo de comuneros influyentes o con el de la clase dirigente o "élite" dándoles acceso al poder político local y con ello, al reconocimiento y prestigio comunitarios (Mosca, 1984), permitía acercarse a la población para implementar sus reformas administrativas y sus campañas chilenizadoras.

De este modo, los inspectores y jueces de Distrito debían controlar y entregar todo tipo de información concerniente a conflictos de tierras, enfrentamientos, festividades, robos, conflictos por el agua, entre otros. Las subdelegaciones se convirtieron en microestructuras administrativas, enclaves políticos en los sectores alejados de los núcleos urbanos. Desde ellas se articulaban a los distritos e inspectorías sobre cuyo personal tenían autoridad legal y comunitaria. En consecuencia, la nueva administración chilena rompió con las estructuras de poder local y, con ello, la delicada red de organizaciones tradicionales propias del escenario andino.

(c) Alberto Díaz Araya. Publicado en AIBR. Revista de Antropología Iberoamericana, Ed. Electrónica 
Las políticas administrativas chilenizadoras en base a subdelegados rurales, daban un importante papel al cargo que ocupaba el juez de distrito en los sectores interiores; cargo que estaba directamente relacionado con el nexo necesario entre la comunidad y el Estado. La asignación de autoridad al juez de Distrito buscaba establecer redes sociopolíticas y administrativas entre el Estado y las comunidades distritales, con el fin de cimentar las políticas que la administración chilena impartía de manera homogénea para todo el territorio en conflicto diplomático.

Dichas políticas fueron destinadas a fortalecer el sentimiento de nacionalidad y patriotismo en la nueva frontera norte de Chile, generando, en ocasiones, medidas represivas frente a los sentimientos anti-chilenos (Díaz et al. 2000: 147). El proceso de chilenización se caracterizó por actuar simultáneamente en diferentes esferas de acción: adelantos en materia de construcción, imposición de la cultura nacional en las escuelas primarias rurales a través de la castellanización y la alfabetización en los poblados rurales, que, en este momento, eran sinónimo de peruanidad o incivilización bajo una lógica Sarmenteana. En el área de Arica se construirían escuelas destinadas a generar conciencia nacional chilena en los educandos, donde los profesores actuarán como verdaderos promotores de la identidad y soberanía patriótica chilena, por lo que el Estado tempranamente destinó maestros normalistas para entregar el servicio de instrucción escolar. Para estimular el proceso de chilenización se ofrecía instrucción sólo a los niños inscritos como chilenos. Así por ejemplo, en un escrito Confidencial a los subdelegados, el Gobernador de Arica, Emiliano Bustos señala que:

Sírvase instruir convenientemente a los Directores de escuelas Públicas y particulares de esa subdelegación en el sentido de que deben concretar la enseñanza que dan solamente a los niños menores de 16 años, quedando prohibido enseñar a leer, escribir, o a firmar a aquellos que tengan mas edad de la indicada, que no sean chilenos netos...

Más adelante en el oficio agrega:

Por otra parte, es necesario tratar de que aprendan, aunque sea Solo a firmar los chilenos netos de esa subdelegación que no lo sepan hacer. Recomiendo especialmente a usted poner en práctica, desde luego esta medida (Oficio $\mathrm{n}^{\circ}$ 18, 16 de Febrero de 1923, Oficios confidenciales recibidos ASP. El subrayado de la cita es del autor del oficio, don Emiliano Bustos, Gobernador de Arica).

Solamente los niños, que aun estaban en proceso de aprendizaje y de instrucción, podían acceder a la educación que el Estado chileno les brindaba y que podían catalogarse por la edad de chilenos. Solo los chilenos deberían tener educación y una instrucción adecuada. De este modo, los campesinos de Putre, que mantuvieran su afiliación peruana, eran marginalizados.

También aplicaron ordenanzas municipales y decretos destinados a modificar las conductas de los aymara. Así por ejemplo, para efectuar fiestas patronales y carnavales, debían solicitar permiso a los carabineros para organizar bandas de Bronces o comparsas de Laquitas. Éstas eran aceptadas, siempre y cuando acompañaran las celebraciones patrióticas (21 de Mayo, 7 de Junio o 18 de Septiembre), y se ejecutaran los himnos y marchas militares chilenas. Así, la chilenización del área significó cambios significativos para la población del actual norte de Chile. El estado desplegó grandes esfuerzos para cimentar las bases del gobierno chileno en todo el sector. 
En los albores del siglo XX, era común solicitar permisos para la entrada de músicos al área preferentemente de instrumentos de viento, como la presente circular № 55 del 13 de Agosto de 1926, la cual dice:

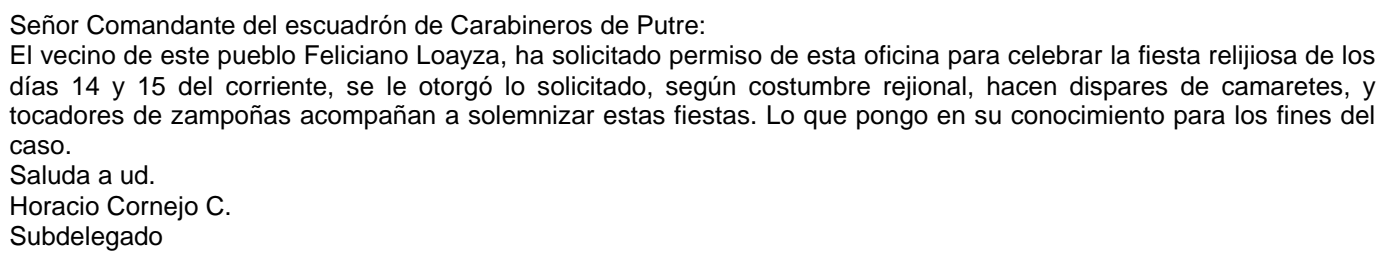

El ritual y la tradición se mantienen, como podemos deducir de la cita anterior, integrando dinámicamente nuevos elementos. Pedir permiso para vivir sus tradiciones parece ser una medida poderosa, ya que cualquier expresión que se alejase de los patrones de identidad chilena, podría ser juzgada como manifestación de querer ser peruanos. Por otro lado, el gobierno local estaba al tanto de las actividades y movimientos de este sector de la población que iba siendo integrado a la administración estatal a través de complejas redes de dependencia.

La incorporación de los campesinos andinos al proceso de nacionalización supuso la reestructuración de sus costumbres de acuerdo a los lineamientos del Estado chileno. Estas políticas administrativas y psicológicas definen los marcos dentro de los cuales pueden mantener sus tradiciones culturales, pero también introducen nuevas prácticas como por ejemplo: la interpretación del himno nacional, el de Yungay, bailar cuecas y todo lo relacionado con el patriotismo chileno (Díaz Araya, 2000).

En esta relación de las personas que componen el comité de fiestas patrias para celebrar el aniversario de la Independencia Nacional el 14 de septiembre de 1925 existe todo un programa que refleja lo dicho:

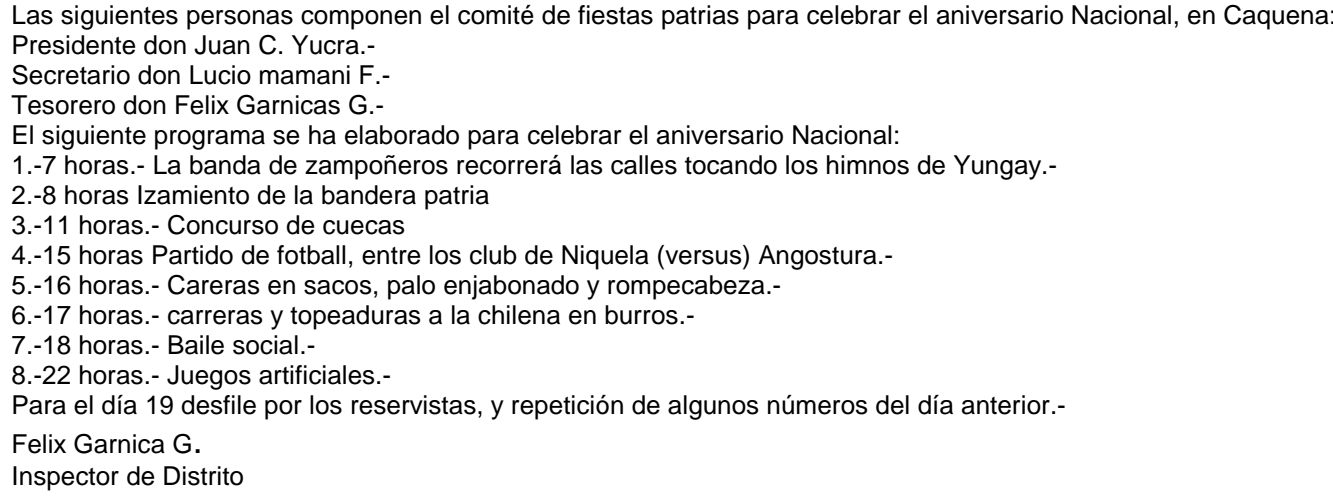

La visión de un Estado chileno rico en recursos (como el salitre), poderoso en influencias a nivel latinoamericano y con un ejército fogueado y vencedor permitió que la óptica Sarmenteana de "Civilización" versus "Barbarie" se aplicase a los pobladores andinos del área de Arica (Díaz, 2003). Se asumía que la idea de progreso chilena o de un Estado "hacedor" se impondría en el comentado Plebiscito. Los ciudadanos apoyarían la gestión del buen gobierno del nuevo Estado, y Chile se 
consolidaría soberanamente en éste territorio. Paralelamente se aplicaba medidas represión indirecta, tales como hacer comparaciones con los países limítrofes de Perú y Bolivia. Por ejemplo la administración publicaba bandos en los que ordenaba que se debía mantener el orden y la limpieza en las casas y calles, haciendo clara referencia a que esto es civilizado en contraste con las costumbres bárbaras de los barrios y poblados del Perú y Bolivia.

Sin duda, quienes sufrieron más violentamente este fenómeno fueron las poblaciones aymara de la zona, que vieron sus tierras comunales y tradiciones -ya aculturadas desde la conquista-, sometidas a la influencia del Estado chileno. Muchas de sus tierras fueron expropiadas, sobre todo en el momento de la construcción del ferrocarril internacional Arica - La Paz, en tal sentido se aprecia:

Se entrega el valor de los terrenos de: Marcelo Gutierrez (\$269.50),N. Almonte (\$198.00); M. Morro (\$245.90); J. Mendoza (\$69.10). Todos éstos terrenos ubicados en el valle de Lluta, para la construción del Ferrocarril Arica - La Paz.( Decreto $n^{\circ}$ 212, en Legajos de Decretos emitidos por la Intendencia de Tacna, 1913, AHVD).

En otro documento se observa:

Los valores de los terrenos a expropiar son: Marcelino Collao (\$118.05); Petrola Alanoca (128.20), del valle de Lluta, para el Ferrocarril Arica - La Paz. (Decreto $\mathrm{n}^{\circ} 224$, en Legajos de Decretos emitidos por la Intendencia de Tacna, 1913, AHVD).

La vida cotidiana fue un tanto hostil para los campesinos aymaras durante la chilenización. Tenían que adaptarse a un nuevo sistema de gobierno. Las tierras comunales pasaron a pertenecer al Ministerio de Tierras y Colonización. Las tierras las compraba el Estado, y los campesinos de los valles bajos estaban obligados a vender, aunque la oferta no fuera la mejor. Más aún, en ocasiones no se respetaban los predios que pertenecían a lugareños con tendencias favorables al Perú. No obstante, hubo aymaras que negociaron sus tierras sin mayor problema y se adaptaron al nuevo Estado que se imponía en la región.

Este es el contexto en que los aymaras tuvieron que desenvolverse. Muchos fueron expulsados otro huyeron por opción al Perú o a Bolivia, otros migraron a los puertos o salitreras. Unos pocos mantuvieron sus actividades productivas, ganaderas y económicas. Entretanto, en la sierra ariqueña lentamente los campesinos andinos anidaron la idea de que estas tierras eran peruanas, y que ellos como peruanos que eran, debían defenderla, a costa incluso del derramamiento de sangre, como a continuación se expondrá.

\section{Resistencia peruana en la sierra de Arica}

Frente a las políticas administrativas implementadas por las autoridades chilenas en Tacna y Arica, la población peruana de la sierra ariqueña vio transformarse el manejo tradicional de los recursos ${ }^{8}$ de uso comunitario y sus manifestaciones festivo-religiosas. Ello fue dando origen a formas de

\footnotetext{
${ }^{8}$ Solicitudes para pastoreo y extracción de yareta y queñoa en cerros anteriormente comunitarios, y ahora considerados como fiscales; elevación de solicitudes para efectuar festividades tradicionales; modificación de costumbres como por ejemplo mantener un ordenamiento y limpieza de las calles "pintar las casas de color blanco con cal". Para mayores antecedentes Díaz et al. (2000).
} 
resistencia. En este sentido, nos parece necesario planteárnos la siguiente pregunta ¿existió en la precordillera de Arica (Putre) una identidad étnica por parte de las autoridades locales?, ¿identidad étnica o identidad sociopolítica o ciudadana?.

Para poder desenmarañar esta compleja madeja, nos centraremos en el análisis de un caso. El de una "autoridad" comunitaria perteneciente a la elite local de Putre a comienzos del siglo XX que, tanto la memoria como las fuentes documentales, describen como un personaje clave en el debate de la identidad nacional durante la chilenización. La figura mencionada es la del comunero putreño Antonio Mollo, personaje de enorme significación e influencia en esta comunidad hacia comienzos del siglo $X X$ y fines del XIX.

memoria putreña menciona que Antonio Mollo habría sido peruano, y llegado al pueblo hacia fines del siglo XIX desde alguna localidad surperuana. Esta sería la explicación evidente de su resistencia a la chilenización. Sin embargo, es necesario preguntarnos cómo éste personaje adquiere notoriedad en el círculo de la elite putreña, y por qué utiliza esta notoriedad para resistir la política chilena.

El conflicto se plantea en torno a la controversia entre la autoridad local comunitaria y la autoridad política. Antonio Mollo que ostentaba el cargo religioso de "fabriquero" de la iglesia del pueblo, se negó a aceptar la autoridad del subdelegado de Putre, quien, de acuerdo con las órdenes del gobernador, priva a la autoridad local de su función tradicional y religiosa de resguardo de la fábrica del templo. La documentación recabada por Tudela nos expresa los primeros conflictos con Mollo, y con ello las primeras reacciones de parte de la autoridad chilena:

Señor Gobernador: Ayer recibí el oficio de Ud. del 25 mayo, juntamente con otro dirigido a Ud., por el Subdelegado de Putre. No es efectivo que los señores Antonio Mollo y Pedro Humires hayan sido nombrados fabriqueros. Les he encargado de las llaves de la iglesia de Putre y Socoroma a condición de que procedan de acuerdo con las autoridades civiles de las respectivas localidades que es deber de todos los habitantes del territorio. Si los expresados señores no lo hacen así, encargaré de las llaves a las Sras. Directoras de las escuelas o a otras personas, previa inspección de lo que sucede (en Tudela, 1994:11).

La intervención del obispo evidencia el rechazo de la iglesia a la insumisión de las autoridades locales:
A mi juicio Ud. debe ser todo benigno que pude con su gente de la subdelegación, pero debe ser inexcavable para hacer respetar las leyes y los bienes del fisco. En cuanto a la iglesia el fabriquero debe proceder de acuerdo con Ud. que es persona que me merece y tiene toda mi confianza. Esta es mi última palabra; si no proceden de acuerdo con Ud. se nombrará otro fabriquero. Yo quiero paz en el pueblo y el respeto a la autoridad" (en Tudela, 1994: 11).

Durante los primeros días de Agosto, surge una disputa por el incierto destino de la chafalonía de la iglesia de Putre en la cuál Mollo servía como fabriquero. De esta forma desde la Gobernación de Arica se emite un oficio dirigido al sub-inspector de policía en comisión en Putre don Juan Dávila con el siguiente contenido:

Sírvase practicar las investigaciones necesaria para averiguar el paradero de la chafalonía perteneciente a la iglesia de Putre, chafalonía que estaba en depósito en poder del señor Antonio Mollo. Para encontrarla proceda a los allanamientos que fuesen necesarios, conseguido el fin que se persigue, la trasladará a esta gobernación, previo inventario que hará levantar el Subdelegado.

Para el procedimiento de todas estas delijencias sirvase proceder de acuerdo con ei Subdelegado señor Herrera.

Dios güe. A Ud.

Luis Arteaga. (Legajo $N^{\circ}$ 590, ASP). 
La polémica por la custodia de los bienes se mantuvo, tomando el Gobernador de la Provincia una activa participación en la investigación, en informe dirigido hacia el promotor fiscal de la provincia, con fecha 9 de Agosto de 1919, se expresa:

Señor Promotor:

Adjunto acompaño a US. Ios antecedentes que se relacionan con la sustracción de algunos bienes de la Iglesia, efectuada por Antonio Mollo, bienes que consisten en ciento dos piezas de plata vulgarmente llamada Chafalonía, con un peso de 29.1/2 libra, como consta del recibo otorgado por el propio Mollo el 23 de Junio de 1902, fecha en que se recibió esas especies para conservarlas en custodia, además de las cuarenta y tres piezas de plata á que se refiere la foja dos de este expediente.

Como en mi calidad de Gobernador del Departamento, me incumben las atribuciones que las leyes de Patronato confieren al Ejecutivo, sírvase US. imponerse de los antecedentes adjuntos y en mérito de ellos, obtener del Juzgado una orden de retención de los bienes de Mollo, para responder á los de la Iglesia que se ha sustraído y que importan seguramente un valor de mas de $\$ 5.000$.

Las investigaciones emprendidas por parte de las autoridades políticas en torno a Mollo tiene un abrupto fin con la entrega voluntaria de Mollo de la chafalonía, En oficio del 28 de Agosto dirigido hacia el promotor fiscal, el Gobernador informa:

Señor Promotor:

Con relación á mis oficios ns590 y 619 de 9 y 22 del presente mes sobre lo que el infrascrito creyó una sustracción de algunos bienes de la Iglesia de Putre que se atribuía a Antonio Mollo, debo manifestar a US. que los referidos bienes consistentes en algunas alhajas de plata, han sido devueltas por Mollo algunas, y otras estaban en la Iglesia de Putre.

Cree el infrascrito, que en vista de lo espuesto, ya no tiene lugar el juicio contra Mollo.

La memoria colectiva de los putreños recuerda a este personaje como quien asumió la defensa de las aguas de la comunidad cuando las Mercedes de Aguas entraron en litigio con parte de la población del sector de Angostura del Valle de Lluta. Don Alberto Primitivo Medina octogenario vecino, rescata de los recuerdos el hecho que:

\begin{abstract}
Antonio Mollo después también tuvo un pleito con los lluteños este caballero; si quería mucho a su pueblo, a Putre...porque los de lluta querían llevarse las aguas de Putre. Ya tenían tramitado en los tribunales y el representante legal de los lluteños era un señor de apellido Mayorga. Entonces, y... y además les inició en belén, que era el primer distrito de esos tiempos. Entonces inició ahí la demanda. Entonces don Antonio dicen que en esa hora se iba p'a Belén, hablaba con el juez y la resolución se la llevaba él mismo a los tribunales de Arica...lo que los lluteños se confiaban con esperar que mandaran esto, porque aquí demoran en llegar... no sé cómo lo mandaban. Antes había un valijero que las llevaba. En cambio Antonio Mollo estaba entre ir y venir, iba y venía hasta que cuando ya salió la sentencia a favor de él, ya listo. Cuando fueron los lluteños a ver eso, caramba que se molestaron. Casi lo linchan a Mayorga porque perdieron el pleito de las aguas en ese tiempo, a don Antonio muchos quedaron agradecidos
\end{abstract}

El papel de Antonio Mollo como líder comunal lo enfrenta a la autoridad chilena y deja de manifiesto la tónica que adquirirían las relaciones entre los comuneros de Putre y el estado chileno durante un extenso período de tiempo.

Hacia el temprano año de 1901, don Antonio Mollo, en fecha cercana al Aniversario patrio peruano, izó en la puerta de su hogar la bandera del Perú y celebró con un grupo de miembros de defensores de la causa peruana denominados "Juventud Putrense"; la actitud, confrontaba las políticas de las autoridades chilenas. El Subdelegado Jaime Fortuño informa a la Gobernación que:

... pongo en conocimiento a Ud que el Domingo 23 i el Miércoles 26 de los corrientes se ha cometido por los vecinos de la Subdelegación en mis manos (Putre) los delitos de sedición, atentado contra la autoridad i desacato contra la misma i ademas se han desobedecido sus mandatos (...) el Domingo 23como a las 12 1/2P.M. me apercibí de que en un edificio que según se me dijo era de propiedad de don Antonio Mollo, había izada una bandera peruana estando parapetados en la casa un grupo llamado "juventud putrense" y el cura párroco de Belén (...) los conferencistas dijeron que no reconocían mi autoridad, que la bandera peruana permanecería izada i que ellos estaban dispuestos a todo... (Legajo $n^{\circ} 213$, en Memoria de la Gobernación de Putre, 2 de Julio de 1901. AHVD) 
La guarnición chilena, ante la revuelta respondió violentamente:

La tropa de húsares i yo hicimos algunas descargas al aire reclamando el orden i como continuaran haciéndonos disparos se trabó un combate que duró como cinco minutos del que resultó muerto uno de los amotinados...el que cayó en el mismo patio de la casa". (Legajo n² 213, en Memoria de la Gobernación de Putre, 2 de Julio de 1901. AHVD)

Este episodio de violencia es temprano ya que; de acuerdo a lo planteado por diversos autores (Tudela, 1994; Pachari, 2000; Díaz et al. 2000), recién a partir de la segunda década del siglo XX comienzan a radicalizarse éstas medidas, en las tierras en litigio. De su lado, las autoridades toman el hecho con cierta tolerancia porque los consideraba como autoridades comunitarias más que como sediciosos nacionalistas ${ }^{9}$.

\section{La tierra como resistencia. Perpetuidad en la terratenencia andina}

Hacia el año 1910, Mollo aparece nuevamente adoptando medidas tendientes a deslegitimar el frágil control chileno en los sectores interiores. Esta vez, el mecanismo de resistencia es mucho mas elaborado.

Dentro de las principales y estrictas medidas de control estatal chileno sobre los sectores rurales, estuvo la apertura de Registros Conservatarios en Arica hacia el año 1885 (Gundermann, 1998). Estos propiciaban la inscripción de la propiedad particular, hayan sido adquiridas por compraventa o por simple ocupación. De esta manera desplazaban el antiguo régimen peruano de Matrícula de Predios Rústicos establecida desde 1876 (Gundermann, 1998).

Quizás la repercusión más fuerte de estas medidas fue que se declararon Terrenos Fiscales todas las propiedades que no estaban inscritas en los registros conservatarios chilenos. Con ello se rompió el control o régimen comunitario tradicional de los terrenos, que eran utilizados para el uso agrícola, pastoreo y el forraje ganadero. El Estado chileno estableció arriendos por el uso de terrenos considerados anteriormente como comunitarios. De esta forma, en los registros de archivo de la Subdelegación de Putre, aparecen una multitud de peticiones de arriendo de pastizales destinados al pastoreo, y permisos para extracción de llareta y queñoa, los cuáles eran administrados anteriormente por normas comunitarias o por arreglos informales.

En este contexto, hemos identificado uno- entre otros- conflictos con la autoridad relacionada a la terratenencia u ocupación de terrenos por parte de la población putreña, y en especial por parte de Antonio Mollo. De esta forma en oficio emitido desde la localidad de Socoroma el 23 de Octubre de 1905, el Subdelegado de Putre, don Emiliano Herrera informa al Gobernador del Departamento de Arica lo que sigue:

Con motivo de que don Antonio Mollo vecino de Putre, está construyendo una casa i un corral en terreno fiscal, cerca de un lugar denominado "Las cuevas", camino de Putre a Choquelimpie...

En días posteriores otra denuncia a la Gobernación informa:

\footnotetext{
${ }^{9}$ Algunos de los tópicos aquí expuestos sobre la figura de Antonio Mollo y su biografía, están en Díaz y Ruz (1998). 
Pongo en conocimiento de Us. que ayer la subdelegación espidió una orden para notificar a don Antonio Mollo, para que suspenda los trabajos que ha empezado en la construcción de una tapia en el camino de "Lluscuma" (camino público de Putre a Ancache y Lluta) para deslindar unos terrenos en blanco que según dice los arrienda i tambien para que deje en su estado primitivo dicho camino...()...Me permito hacer presente a Us. que don Antonio Mollo, vecino de Putre, a mas, de demostrarse en varias ocasiones desobediente a las órdenes del juzgado o de la subdelegacion del lugar i no obstante algunas reconvenciones que se le ha hecho, siempre persiste él en hacer alguna obra nueva como tantas veces lo ha acostumbrado sin consulta ni pedir permiso a la autoridad competente.

Hacia 1910, un grupo de 24 comuneros de Putre decidió inscribir a la "Comunidad de Putre"10 como una propiedad comunitaria que abarcaba una gran extensión de terreno que se extendía hasta territorio actualmente peruano, iba hasta la Quebrada de Caullane o Cavillane por el Este y llegaba hasta las altiplanicies de la actual comuna de General Lagos por el Norte y limitaba al Sur y Este con los terrenos reconocidos por la comunidad de Socoroma y parte de Murmuntane respectivamente.

En este período de litigio entre estados, y conflicto de nacionalidades, no se puede dejar de lado las razones que tuvieron los comuneros para presentar su demanda ante el Estado chileno:

- La utilización de la legislación chilena, como garantía de los derechos sobre sus tierras, surgida por una especie de apuesta ante el inminente plebiscito y la suerte de que estos territorios se mantuvieran en manos del estado peruano, lo que conllevaría a no perder sus derechos legítimos como dueños.

- Recuperar tierras comunitarias y oponerse al arriendo de los terrenos, que el fisco calificaba como fiscales.

- La posibilidad de asegurar sus intereses utilizando la ley del invasor como vehículo para la perpetuación de la propiedad sin el peligro de expropiación, y así, entregarlas a su descendencia, indistintamente fuera cuál fuera el resultado del plebiscito. Por lo cual esta maniobra se transformaría en un instrumento para el resguardo de estas tierras que les pertenecían por uso y costumbres (Gundermann, 1998).

- Por otro lado, cabe mencionar también la posibilidad que abrió el Estado chileno de afectuar la inscripción a título individual. De este modo un número reducido de comuneros (al parecer los más pudientes) pudieron aprovechar la situación para proceder a inscribir los terrenos a su nombre, en desmedro del resto de la población, cuestión que puede ser explicada a su vez por el grado de representatividad de los comuneros titulares (Ruz y Gálvez 2001).

El papel cumplido por Mollo en esta inscripción de propiedad comunitaria, lo recuerda nuevamente el vecino del pueblo de Putre, don Alberto Medina, quién nos menciona algunos alcances que tuvo la formación de esta comunidad restringida. Según narra su abuelo fue convencido por Mollo para inscribir sus derechos y propiedades en comunidad con los 24 vecinos del poblado:

\footnotetext{
${ }^{10}$ Registro Conservatario de Arica a Fojas 152, N0505 CBRA, año 1909; Fojas 153, N0506, año 1910, CBRA; Fojas 153vta №507, año 1910, Fojas 154, N0507, año 1910, CBRA. El documento inicial de 1909-1910 desapareció en el naufragio del barco que los trasladaba hacia Valparaíso para ser trasladado a Santiago. En la actualidad existe una reinscripción de la propiedad realizada en 1991.
}

(C) Alberto Díaz Araya. Publicado en AIBR. Revista de Antropología Iberoamericana, Ed. Electrónica 
Él nunca quiso participar en la formación de la comunidad de Putre; él decía que su padre tenía su título, tiene su papel, "yo no necesito de eso, nosotros somos dueños de aquí y de allá, así que no". ¿qué pasa? Que no podían inscribir las propiedades en comunidad dejando a uno así al margen. En este caso mi abuelo podía reclamar en el pueblo... entonces, dicen que estuvieron como dos o tres años...eh...tratando de convencer al veterano y él dicen que era medio inclinado a esto... mire lo que son las cosas. Curioso no, el abuelo mío también por parte de padre se encargó de tener mucho interés en formar comunidad. Le dijo "mira, Celedonio, te conviene hombre. Tú no tienes participación aquí en Huayllas, no tienes participación en Chapacalla, no tienes participación en varias majadas, ah pero tu me vas a quitar a mi; "bueno, naturalmente que vamos a tener todos participación y tu vas a tener la misma participación". Nunca quiso. Entonces por allá, por el año... entre el año nueve o diez, don Antonio Mollo llegó y trató de convencerlo. Lo llevaba a las fiestas, hasta que en una fiesta de Julio, del 16 de Julio, se celebraba la virgen del Carmen, lo convenció y lo presentó a la comunidad. Entonces entre mareadito el hombre, dice que le... dicen que dijo "lo voy a pensar". Ya, un aplauso y lo regaron al hombre. Entonces ya llegó la fiesta grande del pueblo, Asunta, el 15 de Agosto; ahí lo tenía ya preparado don Antonio Mollo... entonces hizo un gesto en su casa y lo llevó a Celedonio y los llevó a todos los demás, que eran 24 y ahí le sacaron el si. Listo, inmediatamente empezaron.

\section{Desenlace}

La constante hostilidad ejercida por los pobladores pro peruanos, uno de cuyos líderes fue Antonio Mollo, se manifestó a partir de los primeros años de la ocupación chilena y se extendió en el tiempo, provocando con ello una "contrarreacción" del gobierno de Chile. Este fue radicalizando su postura y haciéndola cada vez más violenta (sobre todo entre los años 1920 a 1926). La expulsión de población campesina aymara con claros "sentimientos peruanos" se realizó de forma progresiva y constante. De esta manera se decretó la expulsión de un número considerable de peruanos hacia 1922, que partieron a Bolivia.

Las acciones agitadoras de Antonio Mollo prosiguieron con la finalidad de mantener la lealtad de la población peruana hacia la causa de su país y de volver a la antigua administración peruana al acercarse el Plebiscito de 1926. La realización de una Ronda plebiscitaria legal en 1926, llevó a Mollo de vuelta a Putre llevando propaganda para la causa peruana -recordemos que fue expulsado de la zona en 1922-. Allí los ánimos habían cambiado debido al bombardeo de medidas modernizantes emprendidas por el gobierno chileno en su búsqueda de ganar adeptos a la gestión chilena. La comisión de propaganda no logró su fin y el enfrentamiento con elementos opositores no tardó en llegar. Así, a inicios del mes de Abril de 1926 en la localidad de Putre, Antonio Mollo es muerto en un enfrentamiento con carabineros. El periódico nacionalista peruano "La Voz del Sur" informó sobre el fallecimiento de Mollo: "Ha muerto en Putre don Antonio Mollo, ciudadano peruano, que fue perseguido tenazmente por nuestros adversarios" (La Voz del Sur, Arica, Sábado 10 de Abril de 1926).

La historiografía peruana también trata del tono violento que habrían adquirido las políticas chilenas hacia la segunda década del siglo XX, especialmente en los sectores rurales.

No tengo una lista completa de la gente buena y humilde que murió en 1925 y en 1926 porque era peruana. He aquí una relación provisional de ella, según los datos que he compilado (...) En Azufrera Aguas Calientes: Juan Vargas Barreda. En Palca: Aurelio Flores, José Melchor y Manuel Quispe, y el niño Juan Yufra. (...) En Arica: Miguel Herrera Salas, Teófilo Vilca. En Azapa: Lorenzo Zegarra, Manuel Cruz, Cipriano Quispe, Juan Odzon, Paula Flores de Oviedo. En el Pago de Ayca: Los hermanos Sebastián y José Silvestre Ibarra, Lorenzo Cohaila y su nieto René. En Lluta: Lorenzo Humire. En Villa Industrial: Mateo Lluque, Humberto Colque y Eufemia Ponce. En Huanune: Doroteo y Reflexiones finales 
Antonio Mollo fue un caso significativo para la zona de Putre y sus alrededores, - se presentaron casos similares en otras localidades como Codpa, Belén o Camiña-, donde los comuneros izaron banderas peruanas y desestimaron la autoridad del subdelegado, de los policías y maestros y de la administración pública chilena en general.

El estudio de la situación política y social en la zona de Arica, y en particular de la región interior, deja de manifiesto que el estado chileno actuó de manera directa para ocupar efectivamente estos territorios. Esta actitud generó movimientos o gestos de resistencia nacional a las políticas chilenizadoras. Así, líderes comunales con poder y autoridad local, encabezaron acciones, principalmente en el área de la sierra ariqueña.

Por consiguiente, tenemos que la resistencia no se produjo como respuesta de un grupo de ciudadanos que reclaman sus intereses al Estado sino como la defensa de la causa peruana dentro de un marco jurídico de acuerdos diplomáticos en busca de alternativas para poner fin al conflicto. Por lo tanto sugerimos que es errado pensar que los aymara son un pueblo que se ha mantenido intacto y que no ha asumido posturas ciudadanas. Por el contrario ellos han participado activamente en las políticas nacionales del Estado peruano, -como ha quedado demostrado en este estudio-, así como con las políticas de los estados boliviano y chileno.

Las identidades colectivas son dinámicas, al igual que la cultura; y el ethos de una sociedad o grupo va cambiando y adaptándose a distintos escenarios, sobre todo en territorios caracterizados por la diversidad cultural como es el norte chileno. Antonio Mollo y sus comuneros andinos responden a un momento de la historia reciente caracterizado por el conflicto de identidades nacionales. Los actuales aymara de Tarapacá responden a otras demandas y desafíos que el nuevo milenio les depara, ahora como ciudadanos chilenos. 


\section{Bibliografía}

Anderson, Benedict (1983). Imagined Communities: Reflections on the Origin and Spread of Nationalism. Londres: Verso.

Bengoa, José (2000). Historia del pueblo Mapuche. Siglo XIX y XX. Santiago de Chile: LOM Ediciones.

Braudel, Fernand (1952). Historia y Ciencias Sociales: La larga Duración. Cuadernos Americanos, XVII (6):92-93. México.

De Certau, Michel (1996). La invención de lo cotidiano I. Arte de hacer. México: Universidad Iberoamericana.

Díaz Araya, Alberto (2003). Problemas y perspectivas sociohistóricas en el norte chileno: Análisis sobre la "chilenización" de Tacna y Arica. Revista "Si somos americanos", $V$ (año 4).lquique: Ediciones del Instituto de Estudios Internacionales INTE, Universidad Arturo Prat.

Díaz Araya, Alberto (2000). De acordes andinos al ritmo chileno. Los músicos aymaras durante las primeras décadas del siglo XX en el área rural de Arica. Revista Percepción, 3-4: 83 - 98. Universidad de Tarapacá.

Díaz, Alberto; Mondaca, Carlos y Ruz, Rodrigo (2000). Antecedentes político-administrativos implementados por el Estado chileno en el área rural de Arica, durante 1880-1929. Revista Percepción, 3-4: 7 - 21. Arica, Chile: Taller de Investigaciones Culturales "TINCU".

Diaz, Alberto y Ruz, Rodrigo (1998). Antonio Mollo: Un caso de resistencia a las políticas chilenizadoras en la sierra de Arica. Ponencia presentada en las II Jornadas Nacionales de Historia "Dr. Luis Carreño". Valparaíso, Chile: Universidad de Playa Ancha.

Duby, George y Philippe Ariés (2001). Historia de la vida privada. Madrid: Ediciones Taurus.

Góngora, Mario (1981). Ensayo histórico sobre la noción de Estado en Chile en los siglos XIX y XX. Chile: Ediciones La Ciudad.

Gundermann, Hans (1998). Comunidad aymara, Identidades colectivas y estados nacionales en los albores del siglo XX. En A 90 años de los sucesos de la Escuela Santa María de lquique. Sergio González Miranda, Ed. Santiago de Chile: Ediciones LOM - DIBAM.

Hobsbawn, Eric y Ranger, Terence (1989). La invención de la Tradición. España: Universidad de Cambridge, Ed. Universa.

Larraín, Jorge (2001). Identidad chilena. Santiago de Chile: LOM Ediciones.

Le Goff, Jacques (1988). Historia y memoria. París: Ediciones Gallimard.

Mosca, Gaetano (1984). La clase política. México: Fondo de Cultura Económica.

(c) Alberto Díaz Araya. Publicado en AIBR. Revista de Antropología Iberoamericana, Ed. Electrónica

Vol 1. Num. 2. Marzo-Julio 2006. Pp. 296-310

Madrid: Antropólogos Iberoamericanos en Red. ISSN: 1578-9705 
Pachari, R (2000). La Chilenización de Tacna. Revista Percepción, 3-4: 45-67. Arica, Chile: Taller de Investigaciones Culturales. Universidad de Tarapacá.

Pavilack, Jody (2000) La historia oral: trayectoria, innovaciones y la crítica de los historiadores. Ponencia presentada en Taller de Historia Oral e Historia Local. Centro Martin Luther King. La Habana, Cuba.

Ruz, Rodrigo y Gálvez, Macarena (2001). La historia en la piedra. Putre: Documentos, memoria y arquitectura. Siglos XIX-XX. Arica, Chile: Ediciones TINCU, Ministerio de Educación.

Tudela, Patricio (1994). Chilenización y cambio ideológico entre los aymaras de Arica (1883-1930). Intervención religiosa y secularización». Revista Chilena de Antropología, 12: 35 - 56.

Vial, Gonzalo (1983). Historia de Chile (1891 - 1973). Santiago de Chile: Editorial Santillana.

Villalobos, Sergio (2002). Chile y Perú, la historia que nos une y nos separa. 1535 - 1883. Santiago de Chile: Editorial Universitaria.

Yepes, Ernesto (1999). Un plebiscito imposible. Tacna y Arica 1925-1926. El informe Pershing-Lassiter. Lima: Ediciones Análisis. 